\title{
Methanolysis of Carica papaya Seed Oil for Production of Biodiesel
}

\author{
Foluso O. Agunbiade and Tolulope A. Adewole \\ Department of Chemical Sciences, College of Natural Sciences Redeemer's University, Km 46 Lagos-Ibadan Expressway, \\ Redemption City, Mowe, Ogun State, Nigeria
}

Correspondence should be addressed to Foluso O. Agunbiade; foagunbiade@gmail.com

Received 31 July 2014; Accepted 17 September 2014; Published 25 September 2014

Academic Editor: Xingcai Lu

Copyright (C) 2014 F. O. Agunbiade and T. A. Adewole. This is an open access article distributed under the Creative Commons Attribution License, which permits unrestricted use, distribution, and reproduction in any medium, provided the original work is properly cited.

\begin{abstract}
The future of fossil fuel sources of energy has necessitated the need to search for renewable alternatives. Thus, Carica papaya seed oil (CPSO) was employed as feedstock for the production of biodiesel by methanolysis. The seed was obtained locally, dried, and extracted with n-hexane. The CPSO was analyzed for specific gravity, viscosity, iodine value, and saponification value, among others using standard methods. The oil was transesterified by two-stage catalysis with oil to methanol mole ratio of 1:9. The biodiesel produced was subjected to standard fuel tests. The seed has an oil yield of $31.2 \%$ which is commercially viable. The kinematic viscosity of the oil at $313 \mathrm{~K}$ was $27.4 \mathrm{~mm}^{2} \mathrm{~s}^{-1}$ while that of Carica papaya oil methylester (CPOME) was reduced to $3.57 \mathrm{~mm}^{2} \mathrm{~s}^{-1}$ and the specific gravity was 0.84 comparable with other seed-oil biodiesels and number 2 diesel. Other oil properties were compared favourably with seed oils already documented for biodiesel synthesis. CPOME's cloud and pour points were $275 \mathrm{~K}$ and $274 \mathrm{~K}$, respectively, and relatively higher than other biodiesels and number 2 diesel. CPOME exhibits moderate corrosion of copper strip. The methanolysis improved the fuel properties of the CPOME similar to other biodiesels. CPSO therefore exhibits a potential for biodiesel production.
\end{abstract}

\section{Introduction}

The major parts of all energy consumed worldwide come from fossil sources (petroleum, coal, and natural gas). However, these sources are limited and nonrenewable and will be exhausted in the future. The price volatility of fossilbased fuels, monopoly in the crude-oil market, energy crisis associated with technological advances are some of the justifications for continuous quest and renewed drive for alternative, cheaper, and renewable energy sources $[1,2]$. There is a global clamour for sustainable development and environmental conservation. This has also increased the tempo of researches on the application of biotechnology for other sources of fuel [3]. Thus, there is global interest in sourcing for eco-friendly, clean-burning, and renewable alternative sources of energy such as energy from biomass, wind, solar, hydroelectricity, geothermal, and hydrogen, among others. Alternative and renewable fuels have the potential of solving many of the current social problems and concerns, from air pollution and global warming to other environmental improvements and sustainability issues [4].

Furthermore, over dependency on petroleum reserves for energy supply and the increasing demand for energy are indicators that supply will not meet demand with time. There is therefore need for research efforts in developing vegetable oils and its derivatives as alternate fuels for engines. Biodiesel, one of such alternative fuels, is produced from renewable biological sources such as vegetable oils and animal fats. Biodiesel is a clean burning ester-based, oxygenated fuel synthesized from natural, renewable sources such as virgin or used vegetable oils and animal fats $[5,6]$. The act of producing this fuel, biodiesel, is commonly referred to as transesterification or alcoholysis. The process involves reacting seed oils from some plants, vegetable oils, or animal fats with a short-chain aliphatic alcohol (typically methanol or ethanol) $[7,8]$. The best way to use vegetable oil as fuel is to convert it into biodiesel by alcoholysis which is aimed at increasing the volatility and reducing the viscosity thereby 
improving the fuel properties. The alcoholysis generally may be methanolysis or ethanolysis based on the alcohol used and the production process may be by catalytic or by noncatalytic supercritical processes. Biodiesel fuel production has been attempted through noncatalytic supercritical fluids (methanol and ethanol) method [9]. Some seed oils have been investigated for biodiesel production but competitive applications has limited their commercial exploration $[8,10]$. Some of the seed oils are applied in food and other industrial applications. Thus, the application of some other seed oils that has been classified as underutilized for biodiesel production needs to be further researched into. Therefore, this study is focused on investigating an underutilized seed oil from Carica papaya for production of biodiesel. The annual global production of Carica papaya is placed at over 10 million tons, which places papaya as one of the extremely important fruit crop [11, 12]. The fruit pulp is used as food for human and the foliage is used in fishery livestock feeding [13], but there is no well-documented use for the seed or the seed oil. The aim of this study is therefore to produce biodiesel fuel by methanolysis of Carica papaya seed oils using a two-stage catalytic method and to characterize the fuel relative to other biodiesel and standard diesel fuels.

\section{Materials and Methods}

2.1. Materials. Carica papaya seed used for this study is majorly produced in Mexico, Florida, Hawaii, Nigeria, South Africa, Sri-Lanka, India, Canary Islands, Malaysia, and Australia with Nigeria being the leading producer $(748,000 \mathrm{Mt}$ per annum). It has a typical/average percentage weight composition in the region, seed (8.5\%), skin (12\%), and pulp $(79.5 \%)$ [13]. The seed used for this study was obtained in local Nigerian markets, dried, and grinded; n-hexane solvent was used for oil extraction; potassium hydroxide which was dissolved in glycerol and sulphuric acid was the catalyst used for the two-stage methanolysis reaction with methanol as the transesterifying agent. The first stage catalytic process is to avoid the problem of soap formation with sulphuric acid before the methanolysis with $\mathrm{KOH}$. All reagents used for the methanolysis and the characterizations were of analytical grade.

2.2. Extraction and Characterization of the Seed Oil. The dried, grinded seed was extracted with n-hexane using the Soxhlet extractor until the seed in the Soxhlet has been defatted with resulting cleared coloured n-hexane. The mixture of the seed oils and hexane was separated using a rotary evaporator to guide against denaturing the oil with high heat. The content of the oil in the seed was calculated to evaluate the percentage oil content of the seed. The extracted oil was kept in a refrigerator to guide against peroxidation of the oil until analysis and biodiesel synthesis were completed.

The following characterized steps were undertaken on the seed oil: specific gravity, refractive index using the methods reported by [14-16] while saponification value, iodine value, viscosity, and unsaponifiable matter were determined by the methods described by the Association of Official
Analytical Chemist [17]. The specific gravity was determined with specific gravity bottle and the refractive index was measured with the aid of Abbe refractometer (Optic Ivymen System) at $313 \mathrm{~K}$. Viscosity of the oil was measured using Rotational Viscosimeter (P-SelectraTyp ST-2001L) at $313 \mathrm{~K}$. The saponification value was obtained by adding alcoholic $\mathrm{KOH}$ solution to the sample and heated on a boiling water bath. The excess $\mathrm{KOH}$ was titrated with $0.5 \mathrm{M} \mathrm{HCl}$ using phenolphthalein as indicator to assess the quantity of $\mathrm{KOH}$ used up in saponification [17]. Iodine value was evaluated by weighing about $0.3 \mathrm{~g}$ of the oil accurately and dissolving it in $20 \mathrm{~mL}$ of Wij's solution. The flask was closed, shaken, and kept in the dark for $60 \mathrm{~min}$ at room temperature. Then $20 \mathrm{~mL}$ of potassium iodide solution was added and followed by the addition of $100 \mathrm{~mL}$ of distilled water. The liberated iodine was slowly titrated with $0.1 \mathrm{~N}$ sodium thiosulphate solution until the yellow colour just disappeared and starch solution was added. The resulting blue colour was discharged by further titration with thiosulphate. A blank analysis was carried out alongside. Furthermore, the measuring of the unsaponifiable matter was carried out by taking a known weight ( $2 \mathrm{~g}$ ) of oil, saponifying it with $20 \mathrm{~mL}$ of $0.1 \mathrm{~N}$ ethanolic $\mathrm{KOH}$ under refluxing, and extracted with diethyl ether. The ether was distilled to almost dryness and a few millilitres of acetone were added and evaporated off. The flask is dried at $80^{\circ} \mathrm{C}$ till no further loss occurs and weighed to calculate the unsaponifiable matter.

2.3. Methanolysis Process. The transesterification of the Carica papaya seed oil (CPSO) with methanol was carried out using a two-stage method. Sulphuric acid (2\%) was added to CPSO with continuous stirring with magnetic stirrer for an hour. This first stage acid hydrolysis was followed by the addition of $0.4 \mathrm{~g} \mathrm{KOH}$ catalyst prepared in $0.4 \mathrm{~g}$ glycerol and addition of methanol in oil to methanol mole ratio of $1: 9$ [18]. The mixture was stirred for $2 \mathrm{hrs}$ at $373 \mathrm{~K}$ and at ambient pressure for the conversion of CPSO to the Carica papaya oil methyl esters (CPOME). After the methanolysis of the oil, the glycerol recovery was achieved by the separation of the biodiesel from the glycerol phase in a separating funnel for $4 \mathrm{hrs}$. After the withdrawal of the glycerol, the CPOME was washed with water to remove traces of glycerol. The total ester yield of the biodiesel was calculated using stoichiometric mole ratio of the experimental yield relative to theoretical yield of the CPOME taking the mean molecular weight of the fatty acid in CPSO as $282 \mathrm{~g} / \mathrm{moL}$. The equation of reaction of the methanolysis is presented in Figure 1.

2.4. Fuel Properties. The produced biodiesel was characterized by the determination of specific gravity, viscosity, flash point, pour point, cloud point, copper strip corrosion test, and sulphated ash content $[19,20]$. The viscosity and specific gravity were determined using the same procedure earlier reported above for CPSO.

The cloud point was measured by placing the oil in a thermostated vessel set at $263 \mathrm{~K}$ and the temperature of the oil drops at an interval of $1^{\circ} \mathrm{C}$ from ambient temperature. The temperature at which the oil settles and form cloud 


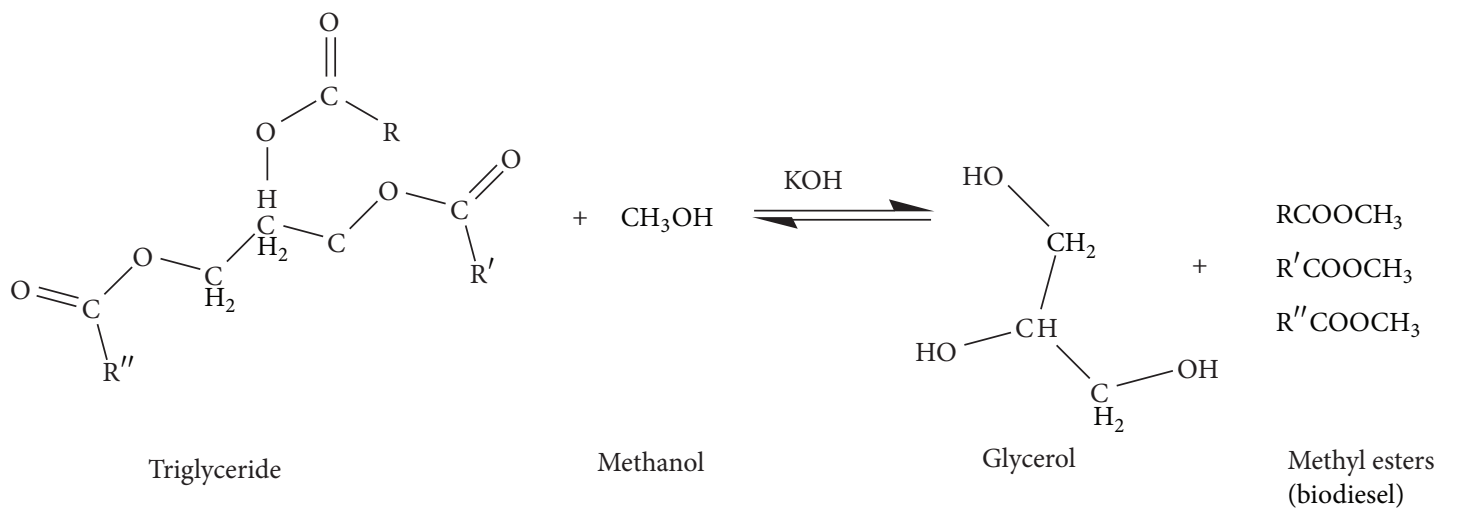

FIGURE 1: Equation of reaction for the methanolysis of triglyceride into fatty acid methyl esters for the production of biodiesel.

was observed as the cloud point. The pour point was also determined on the oil by conditioning the oil in a thermostated vessel at $263 \mathrm{~K}$ and measuring the temperature at which the oil did not flow when tilted. At an interval of $1-2^{\circ} \mathrm{C}$ temperature drop the sample was tilted to observe movement within $5 \mathrm{sec}$. The temperature at which no movement was observed was recorded for the pour point. Flash point was determined in accordance with the modified method for closed cup flash point determination of AOCS [21].

Furthermore, determination of copper corrosion test was carried out using the method of the American Society for Testing and Material (ASTM) [22]. The methyl esters were placed into a chemically clean and dry $25 \mathrm{~mm}$ by $150 \mathrm{~mm}$ test tube; the copper strip was slide into the test tube after being polished. A vented cork was placed at the top of the tube before placing it in a bath maintained at $50 \pm 1^{\circ} \mathrm{C}$. The content of the tube was shielded from strong light during the test. After $3 \mathrm{~h} \pm 5 \mathrm{~min}$ in the bath, the copper strip was examined and compared with standard. The copper strip corrosion test is to assess the corrosion tendency of the fuel on metals and engines.

The sulphated ash was determined to assess inorganic content and gross emission properties of the fuel. This was determined by weighing a known small amount of the sample in a previously weighed crucible. The crucible and sample were heated carefully till the content ignites with flame. The temperature was maintained for uniform burning until no fume or smoke is evolved. The crucible was allowed to cool to room temperature, $2-3 \mathrm{~mL}$ of sulphuric acid $\left(\mathrm{H}_{2} \mathrm{SO}_{4}\right)$ was added, it was heated further until no fume was observed and transferred into muffle furnace and heat at $500^{\circ} \mathrm{C}$ for 1 hour. The temperature of the furnace is allowed to cool and the crucible transferred into desiccators after which it was weighed. The sulphate ash was determined with the expression

$$
\% \text { ash }=\frac{\text { weight of ash }}{\text { weight of oil }} \times 100 .
$$

The cetane number of the methyl esters was calculated using the equation reported by Krisnangkura [23],

$$
\mathrm{CN}=46.3+\frac{5458}{\mathrm{SV}}-(0.225 \times \mathrm{IV})
$$

TABLE 1: Results of characterization of C. papaya seed oil.

\begin{tabular}{lcc}
\hline Parameters & CPSO & LSO $^{\mathrm{a}, \mathrm{b}}$ \\
\hline Specific gravity & 0.926 & 0.924 \\
Kinematic viscosity $\left(\mathrm{m}^{2} \mathrm{~s}^{-1}\right.$ at $\left.313 \mathrm{~K}\right)$ & 27.4 & 27.2 \\
Refractive index & 1.4501 & $\mathrm{nd}$ \\
Saponification value $(\mathrm{mg} \mathrm{KOH} / 100 \mathrm{~g}$ oil) & 107.99 & 187.7 \\
Iodine value (g-I/100 g oil) & 86.7 & 156.7 \\
Unsaponifiable matter $(\%)$ & 1.1 & $\mathrm{nd}$ \\
\hline
\end{tabular}

CPSO: Carica papaya seed oil; LSO: linseed oil; nd: not determined;

${ }^{\mathrm{a}, \mathrm{b}}$ Demirbas 2005 [18]; Demirbas 2009 [1].

where $\mathrm{CN}$ = cetane number, $\mathrm{SV}=$ saponification value, and IV = iodine value.

All analyses were carried out in three replicates to assess reproducibility of method and precision of results.

\section{Results and Discussion}

3.1. Oil Yield and Characterization. The yield of the oil from C. papaya seed was determined as earlier stated. The mean percentage oil yield was $31.18 \pm 0.1 \%$. The result of the oil content of the C. papaya indicates that the seed has relatively high oil content and is considerable for commercial or industrial applications. The oil yield of the seed therefore makes it suitable for consideration in the biodiesel production. Badami and Daulatabad [24] reported the fatty acid composition of Carica papaya seed oil to be lauric acid $(0.4 \%)$; myristic acid $(0.4 \%)$; palmitic acid $(16.2 \%)$; stearic acid (5.0\%); arachidic acid (0.9\%), behenic acid (1.6\%); hexadecenoic acid (0.8\%); oleic acid (74.3\%); linoleic acid $(0.4 \%)$. This implies that the unsaturated fatty acid of the seed oil is more than the saturated one. The implication of this is that the oil will not solidify easily when applied in engines but will flow as oil and not fat. Likewise, palmitic and oleic acids amounting to $90 \%$ of the fatty acid will most likely give good fuel properties. The characterizations carried out on the seed oil were specific gravity, viscosity, refractive index analysis, saponification value, iodine value, and unsaponifiable matter. The results of these characterizations are presented in Table 1. 
TABLE 2: Fuel properties of biodiesel from C. papaya seed oil compared with others.

\begin{tabular}{|c|c|c|c|c|c|}
\hline Parameters & $\mathrm{CPOME}^{\mathrm{a} *}$ & $\mathrm{BOME}^{\mathrm{b}}$ & $\mathrm{LSOME}^{\mathrm{c}}$ & Diesel $^{\mathrm{b}, \mathrm{d}}$ & ASTM B100 \\
\hline Specific gravity & 0.840 & 0.860 & ND & 0.840 & $0.86-0.90$ \\
\hline Kinematic viscosity $313 \mathrm{~K}\left(\mathrm{~mm}^{2} \mathrm{~s}^{-1}\right)$ & 3.57 & 3.98 & 3.36 & 2.60 & $1.9-6.0$ \\
\hline Copper strip corrosion & No. 3 & ND & ND & ND & No. 3 \\
\hline Flash Point $(\mathrm{K})$ & 389 & 348 & 449 & 325 & 403 \\
\hline Pour point $(\mathrm{K})$ & 274 & 270.5 & ND & 231 & 278 \\
\hline Cloud point $(\mathrm{K})$ & 275 & ND & ND & 247 & 278 \\
\hline Sulphated ash content (\%) & 0.02 & 0.017 & 0.01 & 0.01 & 0.02 \\
\hline Cetane number & 77.3 & & & & 47 \\
\hline
\end{tabular}

a This study. ${ }^{*}$ Mean value of triplicate analysis. ${ }^{b}$ Deshmukh and Bhuyar (2009) [2]. ${ }^{\mathrm{c}}$ Demirbas (2009) [1]. ${ }^{\mathrm{d}}$ ASTM 975, ${ }^{\mathrm{e}}$ ASTM 6751-03a.

Specific gravity and viscosity of oil are important properties that are always considered in oil which will serve as feedstock for biodiesel. The specific gravity of the C. papaya seed oil (CPSO) is comparable with specific gravity reported for linseed oil and other seed oils that have been documented as good feedstock for biodiesel $[1,18,25]$. This makes it suitable oil for biodiesel synthesis trial. Further, the viscosity which measures the flow property of a fluid and determines ease of flow of vegetable oil in engine, if used directly, was assessed in the oil. The observed kinematic viscosity of the oil at $313 \mathrm{~K}$ was $27.4 \mathrm{~mm}^{2} \mathrm{~s}^{-1}$ which was comparable with the viscosity also reported for linseed oil and with many other seed oils that have been applied for biodiesel production [18]. The viscosity of CPSO is high for its direct application in engines when compared with $2.60 \mathrm{~mm}^{2} \mathrm{~s}^{-1}$ that has been documented as suitable for petrol diesel [2] or against $4.40 \mathrm{~mm}^{2} \mathrm{~s}^{-1}$ recommended for number 2 diesel fuel by ASTM 975 and documented in literature $[8,18]$. Thus, the reduction of the viscosity of the oil by transesterification is essential to its potential application as biodiesel.

Other parameters studied in the oil which are of interest to biodiesel production were the saponification value and iodine value. The iodine value measures the degree of unsaturation and affects the shelf-life or the long-term keep of the oil. The peroxidation of the oil occurs at the unsaturation point leading to rancidity of the oil and affects the fuel properties of the fuel produced from oil [26]. The iodine value observed for CPSO was $86.7 \mathrm{gI} / 100 \mathrm{~g}$ oil which was relatively lower than linseed oil (Table 1). The fatty acid composition of CPSO as reported by Badami and Daulatabad [24] shows that it is predominantly oleic acid which amounts to $74.3 \%$ of the total fatty acids of the oil. The percentage of unsaturation in CPSO is lower than linseed oil which has C18:1 (18.9\%), C18:2 (18.1\%), and C18:3 (55.1\%) [1, 18]. It therefore implies that CPSO may be more stable to deterioration than the linseed oil. The unsaponifiable matter in CPSO is another important property that may contribute to the fuel properties of its biodiesel product because some of the unsaponifiable matters are waxes which may affect the cloud and pour points of the product. The unsaponifiable matter amounts to $1.1 \%$ which is moderately high.
3.2. Characterization of Biodiesel from C. papaya Seed Oil. After the transesterification of CPSO, the two phases generated were the C. papaya oil methylester (CPOME) and glycerol. The CPOME was separated and characterized based on the following parameters: viscosity, specific gravity, flash point, cloud point, pour point, cetane number, and copper strip corrosion, among others. The values were compared with other biodiesel produced from other feed stocks and with petroleum diesel. The results of the characterization carried out are presented in Table 2 and are discussed in this section.

Specific gravity of biodiesel fuels reported in literature is between the ranges 0.87 and $0.89[18,27]$. The higher the value of specific gravity of the fuel is, the more dense the fuel will be. This will affect a number of the fuel's properties, particularly the flow and the volatility. The specific gravity observed for CPOME was 0.840 which is comparable with petroleum diesel and other biodiesels (Table 2). Generally, the specific gravities of other biodiesels cited were slightly higher than those of petroleum diesel which is 0.840 but that of CPOME is the same as petroleum diesel.

The viscosity is another fuel property which will measure the ease of fuel in engines. A less viscous fuel will flow easily in the engine. Thus, a drop in the viscosity is desirable and improves on the fuel for application in engines. The kinematic viscosity of the biodiesel was significantly reduced from $27.4 \mathrm{~mm}^{2} \mathrm{~s}^{-1}$ for the oil to $3.57 \mathrm{~mm}^{2} \mathrm{~s}^{-1}$ for the biodiesel. This is because of the transesterification that has converted the triglyceride to methyl esters of the fatty acids which have shorter chains than the triglyceride. The viscosity obtained for the CPOME was slightly higher than the standard for petroleum diesel. It was, however, comparable with some seed oils that have been reported for biodiesel production (Table 2).

Moreover, the pour point which is the lowest temperature at which a fuel is observed to flow under the conditions of the test was evaluated in CPOME. A slightly higher pour point was observed for the CPOME $(274 \mathrm{~K})$ than other biodiesels and petroleum diesel which indicates a relatively high amount of wax in fuel form on the unsaponifiable matter in the oil. Generally, pour point data indicates the amount of long-chain 
paraffins found in a fuel. Handling and transporting fuels is difficult at temperatures below their pour points. It therefore implies that biodiesel made from CPSO will be difficult to handle and transport especially in temperate region. Often, chemical additives known as pour point depressants are used to improve the flow properties of such fuel as CPOME. Thus, the use of chemical additive to improve the flow properties of the fuel is recommended for this fuel.

The cloud point of CPOME was also determined. Cloud point of a fluid is the temperature at which dissolved solids are no longer completely soluble, precipitating as a second phase giving the fluid a cloudy appearance. It is the temperature below which wax in diesel or biowax in biodiesels forms a cloudy appearance. The cloud point of CPOME was also higher than other biodiesels and petroleum diesel (Table 2). High cloud point is not also desirable in fuel because the presence of solidified waxes thickens the oil and clogs fuel filters and injectors in engines [27]. The wax also accumulates on cold surfaces (e.g., pipeline or heat exchanger fouling) and forms an emulsion with water. Therefore, cloud point indicates the tendency of the oil to plug filters or small orifices at cold operating temperatures. It may therefore be necessary that the CPOME be applied as blend with petroleum diesel for effective application especially in cold regions of the world.

Another fuel property determined was the cetane number. Cetane number is the ability of fuel to ignite quickly after injection into engines. Higher cetane number ensures better ignition of the fuel in the engine. This is therefore one of the important parameters which are considered during the choice of suitable oil for transesterification for use as biodiesel. Generally, fatty acid methyl esters with higher cetane number are favored for use as biodiesel. However, this increase of cetane number implies decrease in iodine value which means there will be increase in saturated fatty acid composition. This situation will lead to the solidification of fatty acid methyl esters at low temperature typical of temperate region of the world. Therefore, an upper limit of cetane number (65) has been specified in US biodiesel standard [28]. The cetane number obtained for CPOME (77.3) was above the ceiling standard recommended for biodiesel. This result corroborate the results obtained for the pour and cloud point. It may therefore imply that CPSO contains some waxes that are responsible for the obtained results.

The corrosive tendency of the CPOME on engine when applied was assessed by carrying out a copper strip corrosion test. From the method of determination the copper is allowed to stay in the fuel for 4 hours at $313 \mathrm{~K}$ which simulates conditions in which fuel may be applied. The corrosion test shows that the biodiesel moderately corroded the copper strip and may have corrosion tendencies on engines. This may be confirmed further with corrosion studies of the fuel on different alloys and metal materials. Also, the ash test which indicates the amount of metallic constituents in the fuel and the emission or pollution tendency was assessed. The ash left after completely burning the fuel usually consists of stable metallic salts, metal oxides, and silicon oxide. The ash could be further analyzed for individual elements. The sulphated ash obtained for CPOME was comparable with other biodiesels and petroleum diesel (Table 2) which implies that it has acceptable inorganic content. It can also be inferred that the emission properties of the fuel will be moderate.

\section{Conclusions}

The study has attempted to synthesize biodiesel from Carica papaya seed oil and has found that the oil exhibits a potential for biodiesel production. The seed has sufficient oil content and the oil has suitable properties which are comparable with other oils that have been applied for biodiesel production. The transesterification process improved the fuel properties of the CPOME. The CPOME has comparable properties with other biodiesels that have been reported in the literature and with petroleum diesel. High pour point and cloud point was, however, observed for CPOME but can be addressed by using CPOME as blend with petroleum diesel or with addition of pour point depressants.

\section{Conflict of Interests}

The authors declare that there is no conflict of interests regarding the publication of this paper.

\section{References}

[1] A. Demirbas, "Production of biodiesel fuels from linseed oil using methanol and ethanol in non-catalytic SCF conditions," Biomass and Bioenergy, vol. 33, no. 1, pp. 113-118, 2009.

[2] S. J. Deshmukh and L. B. Bhuyar, "Transesterified Hingan (Balanites) oil as a fuel for compression ignition engines," Biomass and Bioenergy, vol. 33, no. 1, pp. 108-112, 2009.

[3] Organization for Economic Co-Operation and Development (OECD), The Application of Biotechnology to Industrial Sustainability, OECD Publication Service, Paris, France, 2001.

[4] H. L. MacLeana and L. B. Laveb, "Evaluating automobile fuel/propulsion system technologies," Progress in Energy and Combustion Science, vol. 29, no. 1, pp. 1-69, 2003.

[5] D. Kusdiana and S. Saka, "Kinetics of transesterification in rapeseed oil to biodiesel fuel as treated in supercritical methanol," Fuel, vol. 80, no. 5, pp. 693-698, 2001.

[6] G. Madras, C. Kolluru, and R. Kumar, "Synthesis of biodiesel in supercritical fluids," Fuel, vol. 83, no. 14-15, pp. 2029-2033, 2004.

[7] J. M. Encinar, J. F. González, J. J. Rodríguez, and A. Tejedor, "Biodiesel fuels from vegetable oils: Transesterification of Cynara cardunculus L. Oils with ethanol," Energy and Fuels, vol. 16, no. 2, pp. 443-450, 2002.

[8] B. K. Bala, "Studies on biodiesels from transformation of vegetable oils for diesel engines," Energy Education Science and Technology, vol. 15, pp. 1-43, 2005.

[9] A. Demirbaş, "Biodiesel from vegetable oils via transesterification in supercritical methanol," Energy Conversion and Management, vol. 43, no. 17, pp. 2349-2356, 2002.

[10] M. I. Al-Widyan and A. O. Al-Shyoukh, "Experimental evaluation of the transesterification of waste palm oil into biodiesel," Bioresource Technology, vol. 85, no. 3, pp. 253-256, 2002.

[11] X. Scheldeman, T. Kyndt, G. C. Coppens d'Eeckenbrugge et al., "Vasconcellea," in Wild Crop Relatives: Genomic and Breeding Resources. Tropical and Subtropical Fruits, C. Kole, Ed., Springer, Berlin, Germany, 1st edition, 2011. 
[12] F. A. Carvalho and S. S. Renner, "A dated phylogeny of the papaya family (Caricaceae) reveals the crop's closest relatives and the family's biogeographic history," Molecular Phylogenetics and Evolution, vol. 65, no. 1, pp. 46-53, 2012.

[13] J. D. C. Medina, G. V. Gutiérrez, and H. S. García, Pawpaw: Post-Harvest Operations: A Report of Food and Agriculture Organization of the United Nation, United Nation, New York, NY, USA, 2003.

[14] D. Pearson, Chemical Analysis of Foods, Churchill Livingstone, London, UK, 7th edition, 1976.

[15] D. R. Osborne and E. Voogt, Analysis of Nutrients in Food, Academic Press, London, UK, 1978.

[16] M. W. Formo, Physical Properties of Fats and Fatty Acids. Bailey's Industrial Oil and Fat Products, vol. 1, John Wiley \& Sons, New York, NY, USA, 4th edition, 1979.

[17] Association of Official Analytical Chemists (AOAC), Official Method of Analysis, AOAC, Washington, DC, USA, 13th edition, 1990.

[18] A. Demirbas, "Biodiesel production from vegetable oils via catalytic and non-catalytic supercritical methanol transesterification methods," Progress in Energy and Combustion Science, vol. 31, no. 5-6, pp. 466-487, 2005.

[19] Y. Ali, M. A. Hanna, and S. L. Cuppett, "Fuel properties of tallow and soybean oil esters," Journal of the American Oil Chemists' Society, vol. 72, no. 12, pp. 1557-1564, 1995.

[20] M. Acaroglu, H. Oguz, and H. Ogut, "An investigation of the use of rapeseed oil in agricultural tractors as engine oil," Energy Sources, vol. 23, no. 9, pp. 823-830, 2001.

[21] American Oil Chemists' Society AOCS, "Official method for flash point closed cupmethod (Modified closed cup method)," ASTM Designation D 93-80, Cc 9b-55, 1997.

[22] American Society for Testing and Material, Copper Strip Corrosion Test D396 Specification for Fuel Oils, ASTM International, Philadelphia, Pa, USA, 2004.

[23] K. Krisnangkura, "A simple method for estimation of Cetane index of vegetable oil methyl esters," Journal of the American Oil Chemists' Society, vol. 63, no. 4, pp. 552-553, 1986.

[24] R. C. Badami and C. D. Daulatabad, "The component acids of Carica papaya (Caricaceae) seed oil," Journal of the Science of Food and Agriculture, vol. 18, no. 8, pp. 360-361, 2006.

[25] J. W. Goodrum, "Volatility and boiling points of biodiesel from vegetable oils and tallow," Biomass and Bioenergy, vol. 22, no. 3, pp. 205-211, 2002.

[26] M. Mittelbach and S. Gangl, "Long storage stability of biodiesel made from rapeseed and used frying oil," JAOCS: Journal of the American Oil Chemists'Society, vol. 78, no. 6, pp. 573-577, 2001.

[27] X. Lang, A. K. Dalai, N. N. Bakhshi, M. J. Reaney, and P. B. Hertz, "Preparation and characterization of bio-diesels from various bio-oils," Bioresource Technology, vol. 80, no. 1, pp. 53-63, 2001.

[28] American Society for Testing and Material (ASTM), "Standard specification for biodiesel fuel blend stock (B100) for middle distillate fuels," ASTM D6751-11, 2011. 


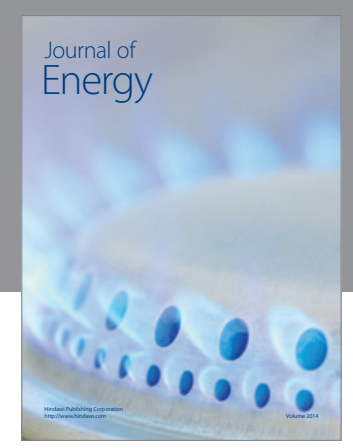

Journal of

Industrial Engineering
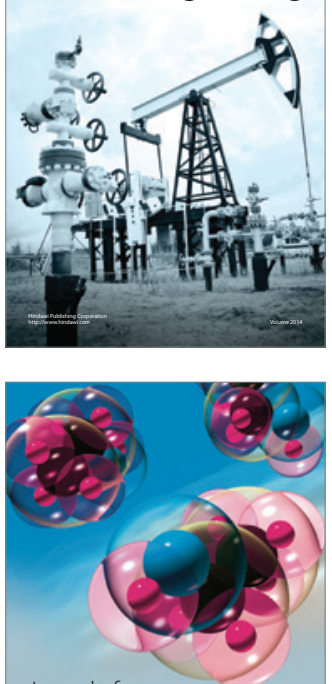

Fuels
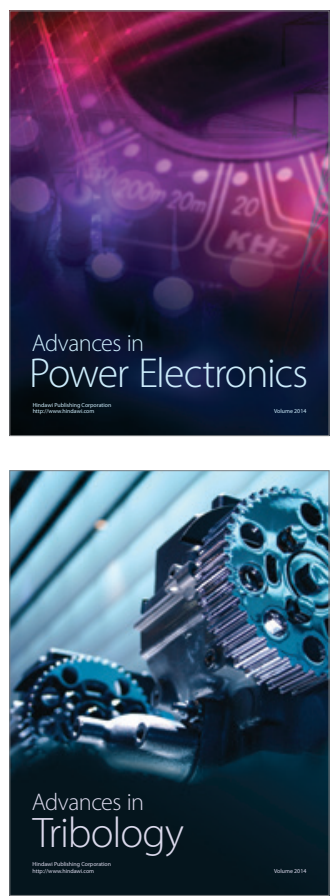

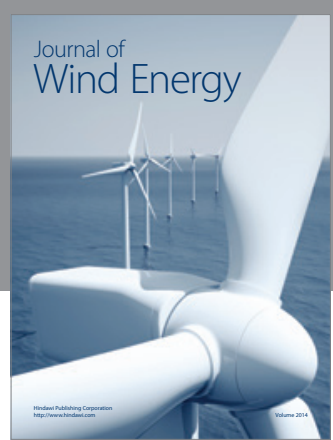

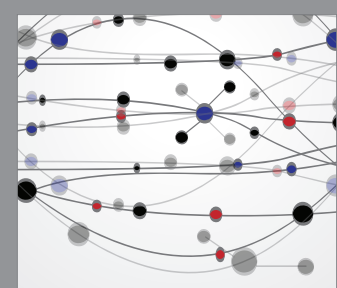

The Scientific World Journal

Submit your manuscripts at http://www.hindawi.com

Journal of

Structures
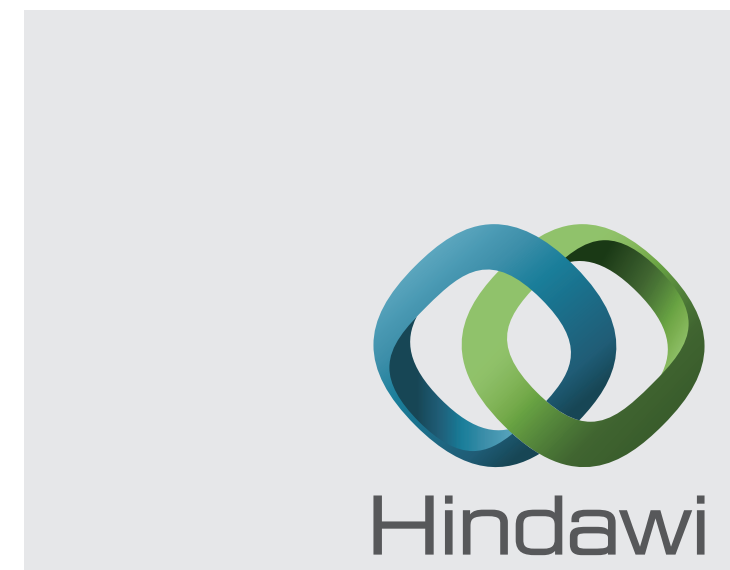

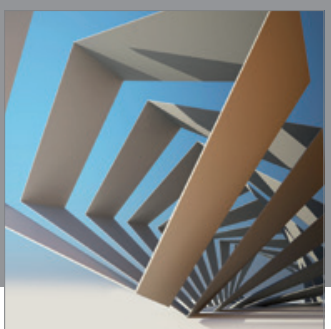

Rotating

Machinery
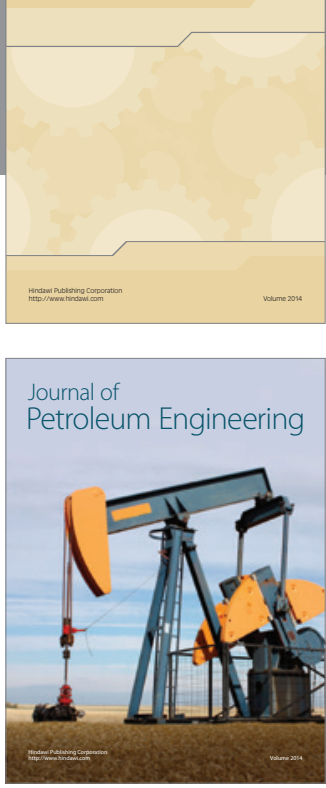

Journal of

Solar Energy
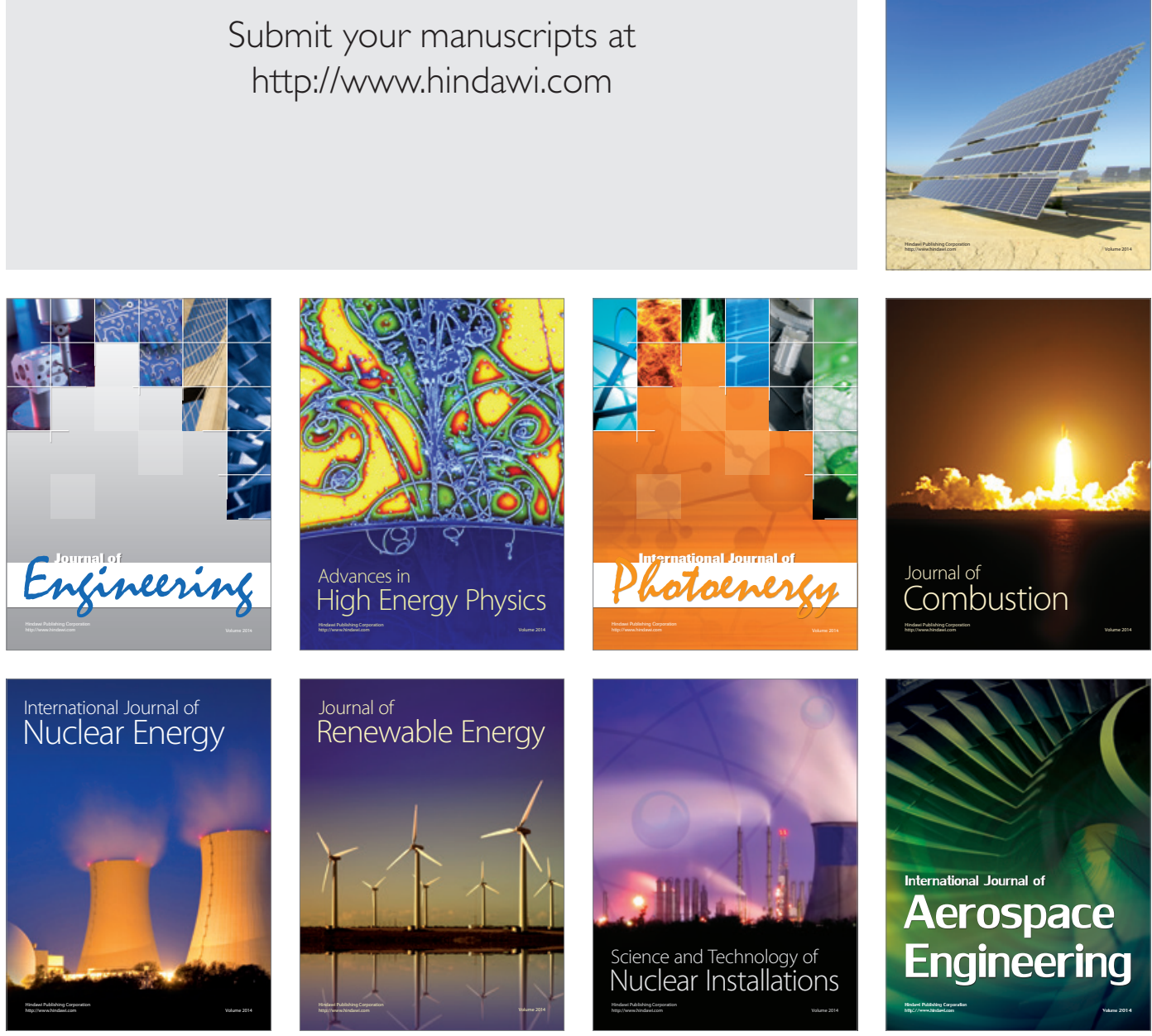